\section{A word from the President of EAHP}

\author{
Petr Horák ${ }^{1,2}$
}

At the beginning of my presidency, I first need to look back and thank all of you, the friends who encouraged me to become a candidate for the Board and EAHP President, the members who gave me their trust, all past presidents, past and current Board members, COO, our staff. Without your work and contributions EAHP would be just an empty shell, and your everyday hard work has made EAHP what it is now-a strong, well-acknowledged, influential and mature professional association. And when I say mature, I do not mean old, despite being the first president who was born after the foundation of EAHP, but rather an organisation which has a clear mission and goals, uses effective policy and communication tools, is well recognised for its role and involvement in many European activities and projects that affect the wellbeing of European patients.

Talking about our goals, it is always our patients who are at the centre of our work. We at EAHP believe that delivering high level pharmaceutical services in hospitals really makes a difference for the patients. Europe is a very diverse landscape, not just geographically and culturally, but also in terms of healthcare systems and resources. However, the needs of patients are universal, and we must always make optimal use of our knowledge and available resources to deliver the best care possible.

EAHP, under Roberto Frontini's leadership and with patient representatives, healthcare professionals and EAHP

\footnotetext{
${ }^{1}$ European Association of Hospital Pharmacists, Brussels, Belgium

${ }^{2}$ Hospital Pharmacy, University Hospital Motol, Prague, Czech Republic
}

Correspondence to Dr Petr Horák; Petr.Horak@eahp.eu members, developed and approved the European Statements of Hospital Pharmacy. The Statements, later endorsed by numerous other stakeholders during Joan Peppard's presidency, points us in the direction we should go. The implementation of certain Statements can be challenging as the data from EAHP surveys suggest. We need to stay in focus and always bear in mind that even small progress counts and makes a difference for the patients. The Statements outline what we should do, but they are not prescriptive and don't say how. It might seem to be nonsense, but in fact it is good, because everyone can adapt their own practice to meet the goals of the Statements. In the end it does not matter if something is achieved by highly sophisticated technology or by pen and paper, it is the result that matters.

When considering the results, I must use this opportunity to remind you, dear colleagues, of how much the documentation of our results and our progress is important. We repeatedly see from the results of EAHP surveys that the publication activity of hospital pharmacists is still lower than expected. I, as a full-time hospital pharmacist, am well aware of the barriers to research and publication. We see substantial under-staffing to meet existing demands, we see new roles for hospital pharmacists, we struggle with implementation of new regulations and policies and we are constantly distracted by medication shortages. I promise that EAHP will work hard to address at least some of these issues. But this is also where the 'chicken and egg' question comes inwe cannot fight under-staffing or develop highly specialised education that would help us in preparing for new challenges without having the evidence about our input to public health. So, in line with the main theme of the last EAHP Congress, please use any possible opportunity to show the world what hospital pharmacists can do!

For the next 3 years, EAHP will be focusing on implementation of the European Statements, continuing the development of the Common Training framework in hospital pharmacy, advocating the needs of patients and our profession at the European level and assisting our members with their national or local activities. We will continue with policies that have a significant impact on public health, such as antimicrobial resistance and prudent use of anti-infectives, addressing medication shortages, defining the role of hospital pharmacists in the area of modern therapies, adopting safe use of new technologies and increasing the safety of patients, just to list some of them. But we will also focus on EAHP itself. This year we will be working on flexible governance to enable EAHP to remain open and adaptable in a fast moving environment. There are a lot of challenges and work ahead, but I am sure that with the help of our members, we will be successful in overcoming any obstacles that might appear in our way. I hope that with your help I will be able to say, as our past presidents could, that EAHP is stronger than before.

I am really looking forward to working with you.

\section{Competing interests None declared.}

Provenance and peer review Commissioned; internally peer reviewed.

C European Association of Hospital Pharmacists 2018. No commercial re-use. See rights and permissions. Published by BMJ.

$$
\text { A) Check for updates }
$$

To cite Horák P. Eur J Hosp Pharm 2018;25:235.

Eur J Hosp Pharm 2018:25:235.

doi:10.1136/ejhpharm-2018-001688 